\title{
Surgical Strategies in the Treatment of Gynecomastia Grade I-Il: The Combination of Liposuction and Subcutaneous Mastectomy Provides Excellent Patient Outcome and Satisfaction
}

\author{
Lars Schröder $^{\mathrm{a}}$ Christian Rudlowski $^{\mathrm{a}} \quad$ Gisela Walgenbach-Brünagel ${ }^{\mathrm{b}} \quad$ Claudia Leutner $^{\mathrm{c}}$ \\ Walther Kuhn ${ }^{a}$ Klaus-Jürgen Walgenbach ${ }^{d}$
}

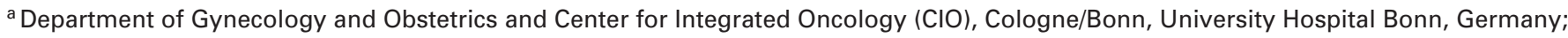
b Institute of Clinical Chemistry and Clinical Pharmacology, University of Bonn, Germany;

${ }^{\mathrm{c}}$ Department of Radiology and Center for Integrated Oncology (CIO), Cologne/Bonn, University Hospital Bonn, Germany;

dDivision of Plastic and Aesthetic Surgery, University Hospital Bonn, Germany
\end{abstract}

\section{Keywords}

Gynecomastia - Liposuction · Subcutaneous mastectomy · Periareolar mastopexy

\section{Summary}

Background: Gynecomastia (GM) is a benign condition with glandular tissue enlargement of the male breast. GM is classified into 4 grades of increasing severity. We describe a series of GM grade I-II, diagnosed, treated surgically and analyzed regarding feasibility, complication rate, and satisfaction. Methods: From 2005 to 2012, a chart review was performed for 53 patients. Preoperative examination included endocrine and urological examination and exclusion of other pathological conditions. The surgical technique consisted of liposuction through an inframammarian-fold incision and excision of the glandular tissue by a minimal periareolar approach. Results: A total number of 53 male patients with 104 breasts were available for analysis. By liposuction, a median of $300 \mathrm{ml}$ (range: 10-1000 ml) was aspirated from each breast and $25.1 \mathrm{~g}$ (range: 3-233 g) gland tissue was resected. Surgery lasted between 25 and $164 \mathrm{~min}$ per patient (median: $72 \mathrm{~min}$ ). 2 postoperative hemorrhages occurred ( $n=2,3.8 \%$ ). 2 patients underwent reoperation due to cosmetic reasons ( $n=2,3.8 \%$ ). Conclusions: This analysis demonstrates that treatment of GM grade I-II can easily be performed by liposuction combined with subcutaneous resection of the glandular tissue as a minimally invasive and low-impact surgical treatment with a low rate of complications and excellent patient satisfaction. Preoperative workup is important to rule out specific diseases or malignancy causing the GM.

\section{Introduction}

Gynecomastia (GM) is a common condition but with variable severity that occurs in men at all ages and refers to a benign condition of breast enlargement with benign glandular proliferation of various causes. It can be found at autopsy in $40-55 \%$ of all men [1-5]. GM most often presents bilaterally, although it can occur asymmetrically. Patients with GM vera most frequently present suffering from aesthetic or psychological symptoms [6].

Three peaks in the prevalence of palpable GM are described: The first one occurs in infants, caused by high materno-placental estrogen levels, and regresses in the first weeks after birth [7]. The second peak appears during puberty between the ages of 13 and 14 years, with a high rate of regression before the 17 th year of life [810]. This transient form is related to the hormonal changes during puberty, which shows an earlier peak of estrogen before testosterone reaches its peak levels. The third peak occurs in men between 50 and 80 years of age related to diverse conditions [4]. Besides physiological categories, GM can be categorized by the triggers (25\% persistent pubertal GM, $10-25 \%$ drug induced, $8 \%$ cirrhosis or malnutrition, $10 \%$ male hypogonadism, $3 \%$ testicular tumors, $1.5 \%$ hyperthyroidism, $1 \%$ chronic renal insufficiency, $25 \%$ idio-

\section{KARGER}

Fax +497614520714

\section{() 2015 S. Karger GmbH, Freiburg}

$1661-3791 / 15 / 0103-0184 \$ 39.50 / 0$
Klaus-Jürgen Walgenbach, MD, PhD 
1.)
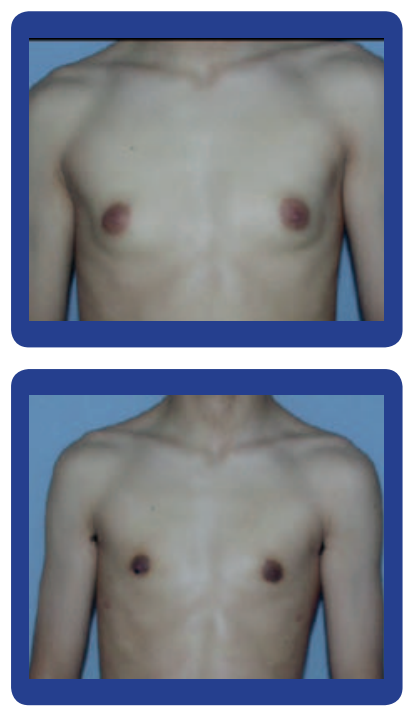

2.)
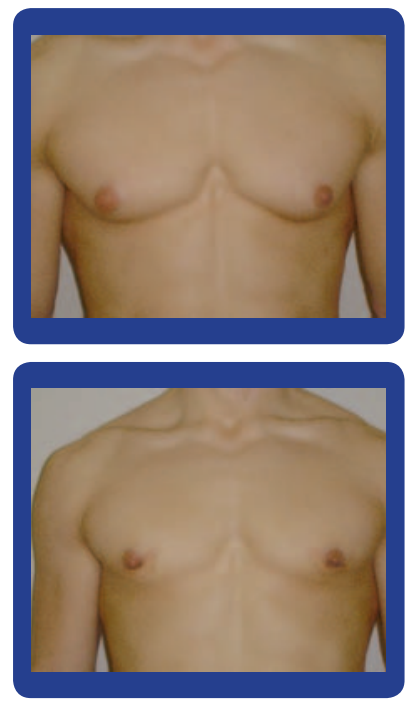

3.)
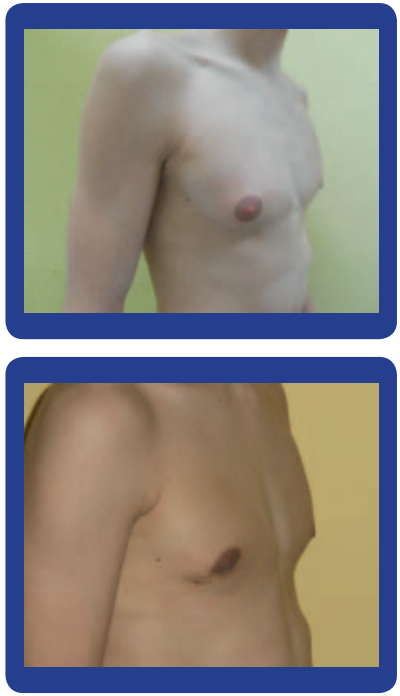
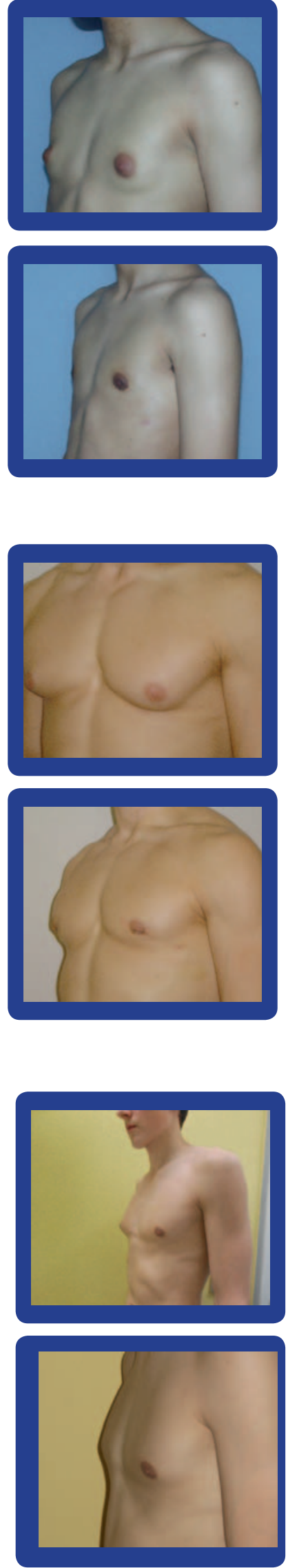
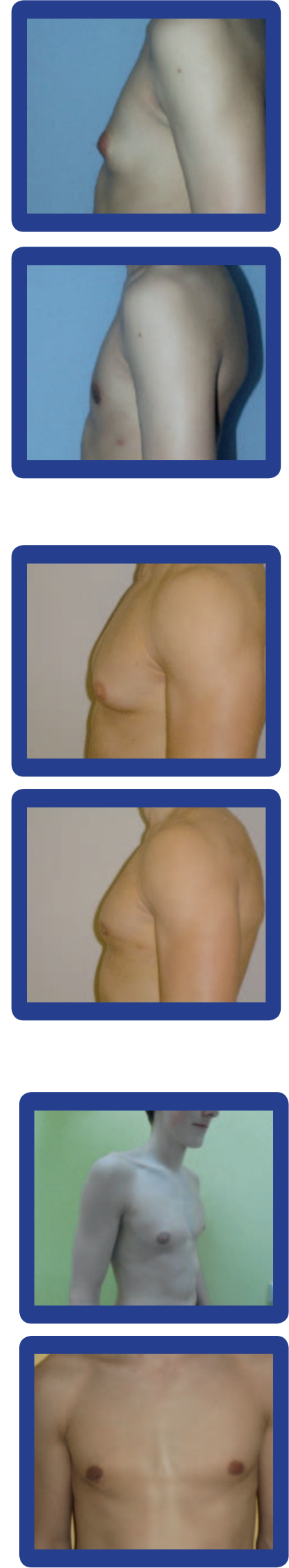

Fig. 1. All pictures of each section (1-3) show the same patient before (upper row) and 3 months after (lower row) surgical therapy (same room, light, camera, camera settings, and photographer). In all cases, a bilateral s.c. mastectomy and a bilateral liposuction were performed. 
pathic) [11]. GM results from an increased volume of glandular tissue or adipose tissue (pseudogynecomastia) or a mixture of both. All causes share an imbalance of androgens and estrogens with a decreased testosterone-to-estradiol ratio, which directly affects the breast tissue [12]. Altered ratios of androgens and estrogens or the increased sensitivity of breast tissue to normal circulating estrogen levels gives rise to ductal hyperplasia, elongation and branching of the ducts correlated with proliferation of fibroblasts and neovascularization $[13,14]$, which altogether form the clinical appearance of GM vera (fig. 1).

To categorize GM clinically, the classification of Simon is most often used [15]. It groups patients into categories according to the size of the GM. Group I is characterized by minor but visible breast enlargement without skin redundancy. Group IIA features moderate breast enlargement without skin redundancy. Group IIB shows moderate breast enlargement with minor skin redundancy. Group III is characterized by gross breast enlargement with skin redundancy that simulates a pendulous female breast. Patients in groups I and II do not require skin excision during potential surgery, but the breast development associated with group III is so marked that excess skin must be removed. Therapy of GM depends on several factors including its duration, grade, etiology, and the presence or absence of clinical symptoms. Treatment options include drug therapy and surgical removal of breast glandular tissue $[16,17]$. After a persistence of 12 months or longer, GM is likely to have reached the fibrotic status, in which conservative treatment is not effective.

The aim of this study was to analyze the surgical strategies in GM grade I-II, their clinical outcome and, based on this data, the development of an algorithm for surgical treatment.

\section{Patients and Methods}

Between 2005 and 2012, we surgically treated 53 patients (a total of 104 breasts) with GM vera grade I-II at the University Hospital of Bonn, Germany. We consecutively performed a chart review regarding the following parameters: personal data, preoperative workup, surgical data, histopathological findings, and follow-up.

All patients underwent presurgical workup containing a physical examination, as well as breast ultrasound and/or mammography. If any abnormalities were seen within the ultrasonography, we initiated additional steps of examination like mammography, breast magnetic resonance imaging (MRI) or fineneedle biopsy.

Low costs, high sensitivity, high specificity, lack of X-rays, and the broad availability make breast ultrasound the first - and, if inconspicuous, only - imaging technique required before surgery. The physical examination consisted of abdominal and urological assessment (including testicular and renal ultrasonography), which is required to exclude differential diagnoses (testicular tumors, malnutrition, underlying liver diseases, hypogonadism, hyperthyroidism, chronical renal insufficiency, and others). Laboratory workup is employed to examine several causes of GM (liver enzymes, creatinine, potassium, sodium, calcium, thyroid-stimulating hormone, free triiodothyronine, luteinizing hormone/follicle-stimulating hormone ratio, testosterone, estradiol, sexual hormone-binding globulins, prolactin, human choriongonadotropin $\beta$ subunit ( $\beta$ HCG)). Preoperative markings were done in vertical position after photographic documentation. In this retrospective analysis, we excluded pseudogynecomastia (pseudogynecomastia refers to an enlargement of the male breast by an excess of adipose tissue without any increase in breast tissue) patients for surgery (exclusion was made clinically and sonographically).

\section{Surgical Technique}

Subcutaneous fatty tissue of the breast was infiltrated with Standard Tumescent Solution [18]. Standard Tumescent Solution consists of $50 \mathrm{ml}$ prilocaine $1 \%, 1 \mathrm{ml}$ epinephrine $(1: 1,000), 8 \mathrm{ml}$ sodium bicarbonate $8.4 \%, 1 \mathrm{ml}$ triamcinolone acetonide, and 1,000 $\mathrm{ml}$ physiological saline [19]. 2 stab incisions per side were made by scalpel in the inframammary fold, 1 at the medial and 1 at the lateral aspect of the inframammary fold. Depending on the thickness of the adipose tissue layer, liposuction of the deeper layers was performed with a 4-mm cannula, followed by superficial or fine-contouring liposuction using a 3-mm cannula. During the liposuction, the gland was partially dissected from the pectoral fascia and the surrounding tissue. After liposuction, the residual gland was removed from the retroareolar area via periareolar incision (in the median third of the areolar circumference), while pulling the nipple-areolar complex ventrally with a double-hook retractor. Preparation was then performed in direction of the thoracic wall, excising the glandular tissue under visual control. Only a thin retroareolar glandular tissue layer was left in place in order to guarantee substantial blood supply to the areolar complex. If necessary, final or additional contour-shaping liposuction was easily performed through the incision under direct visualization. To minimize the wound cavity and the wound surface, 3-0 absorbable adaptive and subcuticular situative sutures were placed, followed by a running intradermal 4-0 absorbable suture. Sterile dressing was applied and moderate pressure was administrated to the thoracic wall by a non-wire, front-closure compression vest for approximately 4 weeks, which reduces hematoma and seroma formation to improve the aesthetic outcome. Regular follow-up visits were performed on the first postoperative day and 2 weeks and 6 months after surgery.

\section{Results}

Clinical data from 53 patients and 104 male breasts were available for analysis. Patients were treated unilaterally in 2 cases $(n=2,3.8 \%)$ and bilaterally in 51 cases (96.2\%), from 2005 to 2012. The mean age was 28.2 years (range: 13-66 years). The only adolescent was 13 years of age, suffering from bilateral GM grade II with severe pain and tenderness, without spontaneous regression for 11 months. The mean weight was $82.6 \mathrm{~kg}$ (range: $60.1-116 \mathrm{~kg}$ ) and the mean body mass index (BMI) was 25.3 (range: 20.5-36.2). Most of the patients underwent a bilateral subcutaneous (s.c.) mastectomy plus bilateral liposuction $(\mathrm{n}=44,83 \%) .4$ patients had only bilateral liposuction (7.5\%) and 3 patients had only a bilateral s.c. mastectomy (5.7\%), whereas the 2 patients with unilateral GM vera were both treated with unilateral s.c. mastectomy plus unilateral liposuction (3.8\%). On average, $300 \mathrm{ml}$ (range: 10-1,000 ml) was aspirated and $25.1 \mathrm{~g}$ (range: 3-233 g) gland tissue was resected from each breast.

Surgery lasted between 25 (unilateral surgery) and 164 min per patient (median $72 \mathrm{~min}$; time from incision to suture). In all cases, the pathological examination revealed GM vera. The only postoperative complication observed was postoperative hemorrhage in 2 cases $(3.8 \%)$. There were no hematomas, seromas, infections, or non-resolving hypesthesias observed during follow-up. 2 patients underwent re-operation due to relapse of the GM after 12 and 15 months $(\mathrm{n}=2,3.8 \%)$. Both patients who relapsed were primarily treated with liposuction alone.

During the follow-up course, all patients expressed satisfaction with the aesthetic results; no pain was asserted. The post-operative residence time in hospital varied from 1 to 3 days (on average, 1.2 days). 


\section{Discussion}

Surgery is by far the main strategy and the most efficient way in the therapy of GM grade I-II in adults. Our results suggest that s.c. mastectomy combined with liposuction should be performed as the preferable operation technique, justified by low complication and recurrence rates and excellent aesthetical outcomes. Using the liposuction technique as the first step leads to the formation of an optically appealing breast and simplifies the following excision steps by defining the glandular tissue [20]. The typical retroareolar rubber most often cannot be removed by the liposuction cannulas alone without complications [21-23], even with special 2.3-mm cannulas [24, 25], sharpened cannulas [26], or other efforts [27] made so far. In our evaluation, the only patients suffering from relapse of GM were those primarily treated by liposuction alone. Therefore, we strongly recommend excising the retroareolar glandular tissue in patients suffering from GM. Omitting the retroareolar gland resection was described as the major complication in trials evaluating liposuction alone [28]. On the other hand, by performing the liposuction as the first step of surgery, the retroareolar gland is demarcated from the surrounding tissue and is therefore easier to resect. Thus, the combination of both methods - liposuction followed by glandular removal - guarantees excellent aesthetic results.

With a post-operative residence time in hospital of 1.2 days on average, costs are low. They are economically lower than those for conservative treatment options or psychological support and, perhaps, for a following surgical approach due to therapy failure in a conservative approach. Liposuction combined with s.c. mastectomy is a very effective treatment with high satisfaction rates together with few complications during the entire course of therapy. By combined surgery, aesthetic satisfaction and relief of pain and tenderness can be rapidly achieved, with a lower rate of recurrences. An accurate presurgical workup is the basis of successful surgery with excellent aesthetic results. Preoperative sonography is strictly recommended to plan the extent of liposuction due to the estimated mastectomy volume. Low costs, high sensitivity, high specificity, lack of X-rays, and the broad availability make breast ultrasound the only imaging technique required before surgery. Only in the case of pathologic findings during the breast ultrasound, other imaging techniques like mammography and, if necessary, fine-needle core biopsy are required. The indication for an adapting liposuction is almost always given, even in thin patients. It is worth discussing whether surgery should be indicated even in obese patients just to give them a positive psychological signal since, even according to the general references, weight loss should be the first step in these patients. Observation for 6-12 months is reasonable in these cases (in the absence of suspected malignancy). Patients with GM caused by drugs should be evaluated for the necessity of taking these drugs or for switching to alternative drugs treating the underlying disease. Conservative trials may be effective in the early, florid phase of GM. 3 types of drugs have been evaluated but not approved by the Food and Drug Administration (FDA) in small cohorts: aromatase inhibitors (AIs), selective estrogen receptor modulators (SERMS), and androgens [17, 29]. Complete regression has rarely been reported (at small percentages); partial regression and especially relief of pain and tenderness have often been reported. Medical treatment for this disease is long lasting; the success rates are low, whereas surgical treatment is mostly straightforward. Patients suffering from pseudogynecomastia may relapse, even if the glandular tissue was excised in toto.

The difficulties of reimbursement of surgery by health insurances and benefactors are nearly impregnable, although the patients frequently present with a high psychological strain. However, these patients could be treated efficiently and cost effectively [30].

Nowadays, the elevated body awareness will raise the discussion of whether surgical therapy of GM should be used more often in the future. Therefore, the indication for surgical therapy of GM should be made more generously and more frequently due to the feasibility shown in this study.

\section{Disclosure Statement}

The authors have no disclosures to make relevant to this manuscript.

\section{References}

1 Braunstein GD: Clinical practice. Gynecomastia. N Engl J Med 2007;357:1229-1237.

2 Rahmani S, Turton P, Shaaban A, Dall B: Overview of gynecomastia in the modern era and the Leeds Gynaecomastia Investigation algorithm. Breast J 2011;17: 246-255.

3 Ley SJ: Cardiac surgery in an era of antiplatelet therapies: generating new evidence. Reflect Nurs Leadersh 2002;28:35.

4 Georgiadis E, Papandreou L, Evangelopoulou C, et al.: Incidence of gynaecomastia in 954 young males and its relationship to somatometric parameters. Ann Hum Biol 1994;21:579-587.

5 Nuttall FQ: Gynecomastia as a physical finding in normal men. J Clin Endocrinol Metab 1979;48:338-340.
6 Rosen H, Webb ML, DiVasta AD, Greene AK, Weldon CB, Kozakewich H, Perez-Atayde AR, Labow BI: Adolescent gynecomastia: not only an obesity issue. Ann Plast Surg 2010;64:688-690.

7 Schmidt-Voigt J: Brustdrüsenschwellungen bei männlichen Jugendlichen des Pubertätsalters (Pubertätsmakromastie). Z Kinderheilkd 1941;62:590-606.

8 Moore DC, Schlaepfer LV, Paunier L, Sizonenko PC: Hormonal changes during puberty: V. Transient pubertal gynecomastia: abnormal androgen-estrogen ratios. J Clin Endocrinol Metab 1984:58:492-499.

9 Harlan WR, Grillo GP, Cornoni-Huntley J, Leaverton PE: Secondary sex characteristics of boys 12 to 17 years of age: the U.S. Health Examination Survey. J Pediatr 1979;95:293-297.
10 Lee PA: The relationship of concentration of serum hormones to pubertal gynecomastia. J Pediatr 1995;86: 212-215

11 Braunstein GD: Gynecomastia. N Engl J Med 1993; 328:490-495.

12 Mathur R, Braunstein GD: Gynecomastia: pathomechanisms and treatment strategies. Horm Res 1997;48: 95-102.

13 Nicolis GL, Modlinger RS, Gabrilove JL: A study of the histopathology of human gynecomastia. J Clin Endocrinol Metab 1971;32:173-178.

14 Bannayan GA, Hajdu SI: Gynecomastia: clinicopathologic study of 351 cases. Am J Clin Pathol 1972;57: 431-437. 
15 Simon BE, Hoffman S, Kahn S: Classification and surgical correction of gynecomastia. Plast Reconstr Surg 1973;51:48-52.

16 Gikas P, Mokbel K: Management of gynaecomastia: an update. Int J Clin Pract 2007;61:1209-1215.

17 Gruntmanis U, Braunstein GD: Treatment of gynecomastia. Curr Opin Investig Drugs 2001;2:643-649.

18 Venkataram J, Venkataram M: Liposuction and the cutaneous surgeon. J Cutan Aesthet Surg 2013;6:129131.

19 Klein JA: Tumescent technique for regional anesthesia permits lidocaine doses of $35 \mathrm{mg} / \mathrm{kg}$ for liposuction. J Dermatol Surg Oncol 1990;16:248-263.

20 Samdal F, Kleppe G, Amland PF, Abyholm F: Surgical treatment of gynaecomastia. Scand J Plast Reconstr Hand Surg 1994;28:123-130
21 Gasperoni C, Salgarello M, Gasperoni P: Technical refinements in the surgical treatment of gynaecomastia. Ann Plast Surg 2000;44:455-458.

22 Courtiss EH: Gynecomastia: analysis of 159 patients and current recommendations for treatment. Plast Reconstr Surg 1987;79:740-750.

23 Lewis CM: Lipoplasty: treatment for gynaecomastia. Aesthetic Plast Surg 1985;9:287-292.

24 Rosenberg GJ: Gynecomastia: suction lipectomy as a contemporary solution. Plast Reconstr Surg 1987;80: 379-385.

25 Rosenberg GJ: A new cannula for suction removal of parenchymal tissue of gynaecomastia. Plast Reconstr Surg 1994;94:548-551.

26 Samdal F, Kleppe G, Abyholm F: A new suction-assisted device for removing glandular gynaecomastia. Plast Reconstr Surg 1991;87:383-384.
27 Luckey RC: Modified technique for correction of gynecomastia. Plast Reconstr Surg 1992;89:767.

28 Fruhstorfer BH, Malata CM: A systematic approach to the surgical treatment of gynaecomastia. Br J Plast Surg 2003;56:237-246.

29 Dobs AS, Meikle AW, Arver S, Sanders SW, Caramelli KE, Mazer NA: Pharmacokinetics, efficacy, and safety of a permeation-enhanced testosterone transdermal system in comparison with bi-weekly injections of testosterone enanthate for the treatment of hypogonadal men. J Clin Endocrinol Metab 1999;84:3469-3478.

30 Wolter A, Scholz T, Diedrichson J, Liebau J: Surgical treatment of gynecomastia: an algorithm. Handchir Mikrochir Plast Chir 2013;45:73-79.

\section{Imprint}

ISSN Print Edition: 1661-3791

ISSN Online Edition: 1661-3805

Journal Homepage: http://www.karger.com/brc

Publication Data: Volume 10, 2015 of 'BreastCare' appears with 6 issues.

Copyright: () 2015 by S. Karger Verlag für Medizin und Naturwissenschaften $\mathrm{GmbH}$, Freiburg (Germany). All rights reserved. No part of the journal may be reproduced in any form without the written permission of the publisher. This includes digitalisation and any further electronic computing, like saving, copying, printing or electronic transmission of digitalized material from this journal (online or offline). Authorization to photocopy items for internal or personal use of specific clients is granted by Karger.

Photocopying: This journal has been registered with the Copyright Clearance Center (CCC), as indicated by the code appearing on the first page of each article. For readers in the US, this code signals consent for copying of articles for personal or internal use, or for the personal or internal use of specific clients, provided that the stated fee is paid per copy directly to Copyright Clearance Center Inc., 222 Rosewood Drive, Danvers, MA 01923 (USA).

A copy of the first page of the article must accompany payment. Consent does not extend to copying for general distribution, for promotion, for creating new works, or for resale. In these cases, specific written permission must be obtained from the copyright owner, S. Karger GmbH, Wilhelmstraße 20A, 79098 Freiburg (Germany).

Disclaimer: The statements and data contained in this publication are solely those of the individual authors and contributors and not of the publisher and the editor(s). The appearance of advertisements in the journal is not a warranty, endorsement, or approval of the products or services advertised or of their effectiveness, quality or safety. The publisher and the editor(s) disclaim responsibility for any injury to persons or property resulting form any ideas, methods, instructions or products referred to in the content or advertisements.

Distribution and Subscription: Karger offers three types of subscription: Print Only, Online Only and the combined Print + Online. The basic annual subscription rate is the same for all three delivery forms; however, a fee for the combined print and online subscription is levied, and there is a postage and handling charge for Print Only and Print + Online. Subscriptions run for a full calendar year. Prices are given per volume.
Print subscription: EUR 180.- + postage and handling.

Online subscription: EUR 180.-

Combined (print + online) subscription: EUR 230.- + postage and handling.

For customers in Germany: Please turn to your bookshop or to

$\mathrm{S}$. Karger Verlag für Medizin und Naturwissenschaften $\mathrm{GmbH}$

Wilhelmstr. 20A, 79098 Freiburg (Germany)

Tel. +497614520 70, Fax +497614520714

E-mail information@karger.com

For customers in all other countries: Please contact your bookshop or

S. Karger AG, Allschwilerstr. 10, 4009 Basel (Switzerland)

Tel. +41 6130611 11, Fax +41613061234

E-mail karger@karger.com

Advertising: Correspondence should be addressed to the publisher.

S. Karger Verlag für Medizin und Naturwissenschaften $\mathrm{GmbH}$

Attn. Ellen Zimmermann (Head of Marketing)

E-mail e.zimmermann@karger.com

Price list No. 10 of January 1, 2015 is effective.

V.i.S.d.P. (Person responsible according to the German Press Law): Sibylle Gross

Type setting and printing: Kraft Druck GmbH, 76275 Ettlingen, Germany.

Bibliographic Services

Science Citation Index Expanded

SciSearch

Journal Citation Report/Science Edition

PubMed Central

\section{KARGER}

Fax +497614520714 Information@Karger.com www.karger.com 